\title{
Dependence of Biphasic Heart Rate Response to Sustained Hypoxia on Magnitude of Ventilation in Man
}

\author{
M. Tanaka, S. Takaishi, T. Ohdaira, T. Kobayashi, \\ R. Maruyama, B. Ahn, A. Masuda, \\ S. MASUYAMA*, and Y. HONDA \\ Departments of Physiology and *Chest Medicine, School of Medicine, \\ Chiba University, Chiba, 280 Japan
}

\begin{abstract}
We studied the dynamic profile of respiratory and circulatory activities during sustained isocapnic hypoxia in healthy males. In response to end-tidal $P_{\mathrm{O}_{2}}$ depression to about 55 Torr, minute ventilation first increased briskly and then depressed. Such biphasic response to hypoxia was also observed in the heart rate. A significantly positive correlation was found between the magnitudes of ventilatory and heart rate responses. No significant increases were found in arterial noradrenaline and potassium, but adrenaline significantly increased gradually with time. Furthermore, when $V \mathrm{~T}$ and $f$ were intentionally maintained constant so as to prevent the biphasic ventilatory change, the biphasic heart rate response previously seen in spontaneous hypoxic breathing disappeared. We suggest that the heart rate is mainly determined by the pulmonary vagal inflation reflex. Putative neurochemicals to elicit hypoxic ventilatory depression, and arterial catecholamine and potassium concentrations may not be directly related to the specific profile of the biphasic heart rate response during moderate hypoxia.
\end{abstract}

Key words: hypoxic ventilatory response, moderate hypoxia, hypoxic depression, catecholamine, $\mathrm{K}^{+}$.

In adult humans, the ventilatory response to sustained hypoxia is biphasic, characterized by an initial increase followed by a decline [1,2]. A similar biphasic response in the heart rate (HR) during hypoxia was also observed in our previous study [3]. However, its extent and detailed nature remain unclear. As to the biphasic ventilatory response to hypoxia, the early augmentation is derived from peripheral chemoreceptor stimulation and the subsequent depression is assumed to be attributable to the central depressant action of hypoxia [1,4] or adaptation of the afferent activities of the peripheral chemoreceptors [5-7]. Animal studies confirmed the parallel change between ventilation and $\mathrm{HR}$ via the Hering-Breuer

Received on April 2, 1992; Accepted on August 24, 1992 
pulmonary inflation reflex [8-10]. Therefore, the time-course of the HR change may possibly be explained by this reflex mechanism.

A number of recent studies have suggested that hypoxic ventilatory depression is mediated by diverse neurotransmitters and neuromodulators, that is, dopamine, gamma-aminobutyric acid (GABA), adenosine and so on [1,11-16]. The effect of these neurochemicals on HR is yet to be fully clarified. Furthermore, it has been shown that hypoxia enhanced sympathetic activities [17] and increased the release of catecholamines [17-19] and $\mathrm{K}^{+}[19-21]$. These effects may play some roles on ventilatory and cardiovascular activities. $\mathrm{K}^{+}$and dopamine are known to affect peripheral chemoreceptor discharges $[22,23]$. In addition to these observations, the release of catecholamines has been shown to diminish the plasma $\mathrm{K}^{+}$concentration $[19,24]$.

The present study was undertaken to elucidate the correlation between ventilatory and circulatory activities during sustained isocapnic hypoxia.

\section{METHODS}

Subjects. Eleven heathly male volunteers ranging in age from 19 to 42 years were studied. They had some knowledge of, and familiarity with the respiratory apparatus, but they were not told the experimental purpose. Although they were instructed in the experimantal procedures, they were not informed of any results until all the studies had been completed. All subjects gave their informed consent. The subjects were kept free of food and caffeine intake for at least $2 \mathrm{~h}$ prior to the experiment.

Experimental setup. The subjects breathed in a closed circuit containing a 10 $l$ rubber bag. End-tidal $P_{\mathrm{O}_{2}}\left(P_{\mathrm{ET}_{\mathrm{O}_{2}}}\right)$ was maintained at about 55 Torr by adjusting the inflow of $\mathrm{N}_{2}$ or $\mathrm{O}_{2}$ to the circuit. End-tidal $P_{\mathrm{CO}_{2}}\left(P \mathrm{ET}_{\mathrm{CO}_{2}}\right)$ was maintained at a room-air breathing level by adjusting the by-pass flow to a $\mathrm{CO}_{2}$ absorber.

A hot-wire flowmeter (Minato, RF-H) was inserted between the mouthpiece and a one-way valve in order to detect the breath-by-breath respiratory flow. The flow signal was electrically integrated to obtain tidal volume $(V \mathrm{~T}) . \quad P \mathrm{ET}_{\mathrm{O}_{2}}$ and $P_{\mathrm{ET}_{\mathrm{CO}}}$ were observed by a rapid response $\mathrm{O}_{2}$ and $\mathrm{CO}_{2}$ analyzer (San-ei, $1 \mathrm{H} 21$ ). Arterial $\mathrm{O}_{2}$ saturation $\left(\mathrm{Sa}_{\mathrm{O}_{2}}\right)$ and heart rate $(\mathrm{HR})$ were measured by using an ear oximeter (Ohmeda, Biox III). A catheter was inserted into the radial artery to measure blood pressure (Bp) by using a pressure transducer (San-ei, Tokyo), which was calibrated with a mercury manometer and positioned approximately at the level of the heart.

Experimental procedures. Experiment 1. Sustained isocapnic hypoxia with spontaneous breathing: Eight subjects participated in the study. After sufficient rest, the subjects were connected to a breathing circuit through the mouthpiece with a one-way valve and breathed room air. When stable breathing and HR had been achieved, usually after about $5 \mathrm{~min}$, the valves in the circuit were turned at the end of expiration to cause re-breathing from the rubber bag initially filled with gas with 
$P_{\mathrm{O}_{2}}$ at about 55 Torr. During hypoxia $P_{\mathrm{ET}_{\mathrm{CO}}}$ was maintained at the air-breathing level. Isocapnic hypoxia was sustained for $20 \mathrm{~min}$ with either continuous arterial Bp measurement, or with arterial blood sampling. Arterial blood samples were taken just before and at 5,10, and 15 min during the hypoxic runs. Each sample was divided into two parts. One was stored in a heparinized syringe to measure the potassium ion concentration $\left(\mathrm{K}^{+}\right)$and blood gases, and the other portion was transferred to a chilled test tube (containing ethylenediaminetetraacetate- $2 \mathrm{~K}$ ). The latter sample was centrifuged and its plasma was stored at $-80^{\circ} \mathrm{C}$ to measure adrenaline and noradrenaline concentrations. Adrenaline and noradrenaline were analyzed by high pressure liquid chromatography (trihydroxyindole post-label method).

Experiment 2. Sustained isocapnic hypoxia with $V_{\mathrm{T}}$ and $f$ maintained at a given level: Five subjects participated in the study. Two of them had also participated in Experiment 1. They were subjected to the same hypoxic conditions as Experiment 1, except that $V \mathrm{~T}$ and $f$ were intentionally maintained constant by observing an oscilloscope screen which had been calibrated for $V \mathrm{~T}$ and $f$ beforehand. The subjects were instructed to try to maintain the peak $V_{T}$ and $f$ levels detected by Experiment 1. However, when $V_{T}$ was kept constant at the desired level, $f$ sometimes slightly exceeded the frequency in Experiment 1 . It must be noted in this connection that some subjects felt slight dyspnea during this procedure. Thus, the effect of preventing $V T$ depression on HR was observed.

Data analysis. The statistical significance of the absolute values in each $5 \%$ in $p$ value was considered significant.

\section{RESULTS}

When $F_{\mathrm{I}_{\mathrm{O}_{2}}}$ was lowered abruptly, $P \mathrm{ET}_{\mathrm{O}_{2}}$ dropped promptly to reach the target $P \mathrm{ET}_{\mathrm{O}_{2}}$ of about 55 Torr within 1-2 min. Thereafter, $P_{\mathrm{ET}_{\mathrm{O}_{2}}}$ was maintained at this level for $20 \mathrm{~min}$. The average responses to sustained isocapnic hypoxia with spontaneous breathing by the 8 subjects are presented in Table 1. Figure 1a illustrates an example of actual experimetal recordings during hypoxic exposure with spontaneous breathing of one subject.

$\dot{V}$ E initially increased by a mean of about $60 \%\left(p<0.01\right.$ : vs. control) as $P_{\mathrm{ET}_{\mathrm{O}_{2}}}$ fell and then gradually decreased by about $40 \%$ at $15 \mathrm{~min}(p<0.05$ : vs. the value at $5 \mathrm{~min}$ ). This biphasic change in $\dot{V}_{\mathrm{E}}$ was found to be due mainly to the change in tidal volume but not the respiratory frequency.

As to the cardiac parameters, HR initially increased to about $117 \%$ of control as $P_{\mathrm{Er}} \mathrm{O}_{2}$ fell, and then gradually decreased to about $112 \%$ at $15 \mathrm{~min}(p<0.05$ : vs. at the value at $5 \mathrm{~min}$ ). On the other hand, systolic and diastolic blood pressure increased and decreased, respectively, so mean blood pressure remained unaltered during hypoxia.

There was no increased in arterial noradrenaline and $\mathrm{K}^{+}$, but arterial adrenaline increased gradually $(p<0.05)$.

Vol. 42 , No. 6, 1992 
Table 1. The time-course of measured parameters before and during hypoxic challenge with free breathing obtained from 8 subjects.

\begin{tabular}{|c|c|c|c|c|}
\hline & \multirow{3}{*}{ Air-breathing } & \multicolumn{3}{|c|}{ Sustained isocapnic hypoxia } \\
\hline & & \multirow{2}{*}{$\frac{\text { Initial period }}{5 \text { th min }}$} & \multicolumn{2}{|c|}{ Latter period } \\
\hline & & & 10th min & 15 th $\min$ \\
\hline$P_{\mathrm{ET}_{\mathrm{O}_{2}}}$ (Torr) & $112.1 \pm 9.8$ & $55.5 \pm 4.0^{* *}$ & $54.3 \pm 5.4^{* *}$ & $55.7 \pm 4.7 * *$ \\
\hline$P \mathrm{ET}_{\mathrm{CO}_{2}}$ (Torr) & $42.3 \pm 4.3$ & $42.0 \pm 4.7$ & $42.8 \pm 4.2$ & $43.3 \pm 4.4$ \\
\hline$V \mathrm{~T}(l)$ & $\begin{array}{c}0.57 \pm 0.1 \\
(100)\end{array}$ & $\begin{array}{l}0.87 \pm 0.14^{* *} \\
\quad(152.6)\end{array}$ & $\begin{array}{l}0.82 \pm 0.23^{*} \\
(143.1)\end{array}$ & $\begin{array}{c}0.80 \pm 0.13^{* *, \dagger} \\
(132.2)\end{array}$ \\
\hline$f$ (breaths/min) & $\begin{array}{c}13.7 \pm 4.5 \\
(100)\end{array}$ & $\begin{array}{c}15.0 \pm 0.66 \\
(108.9)\end{array}$ & $\begin{array}{c}14.6 \pm 7.3 \\
(103.8)\end{array}$ & $\begin{array}{c}13.3 \pm 4.3 \\
(99.1)\end{array}$ \\
\hline$\dot{V}_{\mathrm{E}}(l / \mathrm{min})$ & $\begin{array}{c}8.2 \pm 3.5 \\
(100)\end{array}$ & $\begin{array}{c}13.3 \pm 4.9^{* * *} \\
(162.0)\end{array}$ & $\begin{array}{c}11.7 \pm 3.7^{* \dagger}+ \\
(142.7)\end{array}$ & $\begin{array}{c}11.0 \pm 3.0^{*, \dagger} \\
(138.1)\end{array}$ \\
\hline HR (beats/min) & $\begin{array}{c}67.9 \pm 9.3 \\
(100)\end{array}$ & $\begin{array}{c}79.4 \pm 9.2^{* *} \\
(117.0)\end{array}$ & $\begin{array}{c}76.7 \pm 11.2^{* * *} \\
(112.5)\end{array}$ & $\begin{array}{c}76.4 \pm 10.4^{* *, \dagger} \\
(112.0)\end{array}$ \\
\hline $\mathrm{SBP}(\mathrm{mmHg})$ & $\begin{array}{c}127.9 \pm 14.0 \\
(100)\end{array}$ & $\begin{array}{c}130.2 \pm 15.9 \\
(102.2)\end{array}$ & $\begin{array}{c}131.0 \pm 15.7 \\
(103.2)\end{array}$ & $\begin{array}{c}131.3 \pm 17.5 \\
(102.4)\end{array}$ \\
\hline $\mathrm{DBP}(\mathrm{mmHg})$ & $\begin{array}{c}67.3 \pm 9.6 \\
(100)\end{array}$ & $\begin{array}{c}66.1 \pm 9.4 \\
(97.3)\end{array}$ & $\begin{array}{c}65.7 \pm 9.4 \\
(98.5)\end{array}$ & $\begin{array}{c}65.0 \pm 10.8 \\
(96.4)\end{array}$ \\
\hline $\mathrm{MBP}(\mathrm{mmHg})$ & $\begin{array}{c}87.4 \pm 10.0 \\
(100)\end{array}$ & $\begin{array}{c}86.9 \pm 9.3 \\
(99.7)\end{array}$ & $\begin{array}{c}87.9 \pm 11.1 \\
(101.0)\end{array}$ & $\begin{array}{c}86.5 \pm 11.4 \\
(99.3)\end{array}$ \\
\hline $\mathrm{PP}(\mathrm{mmHg})$ & $\begin{array}{c}61.2 \pm 11.0 \\
(100)\end{array}$ & $\begin{array}{l}63.3 \pm 13.8 \\
(103)\end{array}$ & $\begin{array}{c}64.0 \pm 9.3 \\
(106)\end{array}$ & $\begin{array}{l}66.2 \pm 12.2 \\
(108)\end{array}$ \\
\hline $\mathrm{A}(\mathrm{ng} / \mathrm{ml})$ & $\begin{array}{l}0.11 \pm 0.05 \\
(100)\end{array}$ & $\begin{array}{c}0.13 \pm 0.07 \\
(118)\end{array}$ & $\begin{array}{l}0.15 \pm 0.09 * \\
(136)\end{array}$ & $\begin{array}{l}0.15 \pm 0.09^{*} \\
(136)\end{array}$ \\
\hline NA (ng/ml) & $\begin{array}{c}0.23 \pm 0.07 \\
(100)\end{array}$ & $\begin{array}{l}0.23 \pm 0.06 \\
(100)\end{array}$ & $\begin{array}{l}0.23 \pm 0.04 \\
(100)\end{array}$ & $\begin{array}{l}0.23 \pm 0.03 \\
(100)\end{array}$ \\
\hline $\mathbf{K}^{+}(\mathrm{mmol} / l)$ & $\begin{array}{c}4.03 \pm 0.21 \\
(100)\end{array}$ & $\begin{array}{c}3.90 \pm 0.24^{* *} \\
(97.2)\end{array}$ & $\begin{array}{c}3.95 \pm 0.22 * \\
(98.2)\end{array}$ & $\begin{array}{c}3.86 \pm 0.13 * * \\
(96.4)\end{array}$ \\
\hline
\end{tabular}

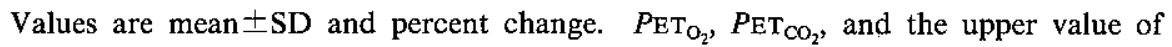
other parameters are the mean of absolute values obtained from 8 subjects. The lower figures in parentheses show the average response in terms of percent change in each subject. *** Significantly changed from the control value at 5 and $1 \%$ levels, respectively. ${ }^{\dagger}$ Significantly changed from the initial period (5th min) value at $5 \%$ level.

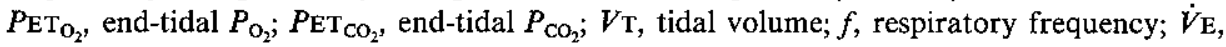
minute ventilation; HR, heart rate; SBP, systolic blood pressure; DBP, diastolic blood pressure; MBP, mean blood pressure; PP, pulse pressure; A, adrenaline; NA, noradrenaline; $\mathrm{K}^{+}$, potassium.

During hypoxic exposure, the rate of increase in HR was well correlated with the rates of increase in $V_{\mathrm{T}}$ and $\dot{V}_{\mathrm{E}}$ (Fig. 2).

Figure $1 \mathrm{~b}$ illustrates a typical example of the sustained isocapnic hypoxia with constant $V_{\mathrm{T}}$ in one subject. When $V_{\mathrm{T}}$ was intentionally controlled to prevent the biphasic ventilatory response, the biphasic HR response previously seen in sponta- 


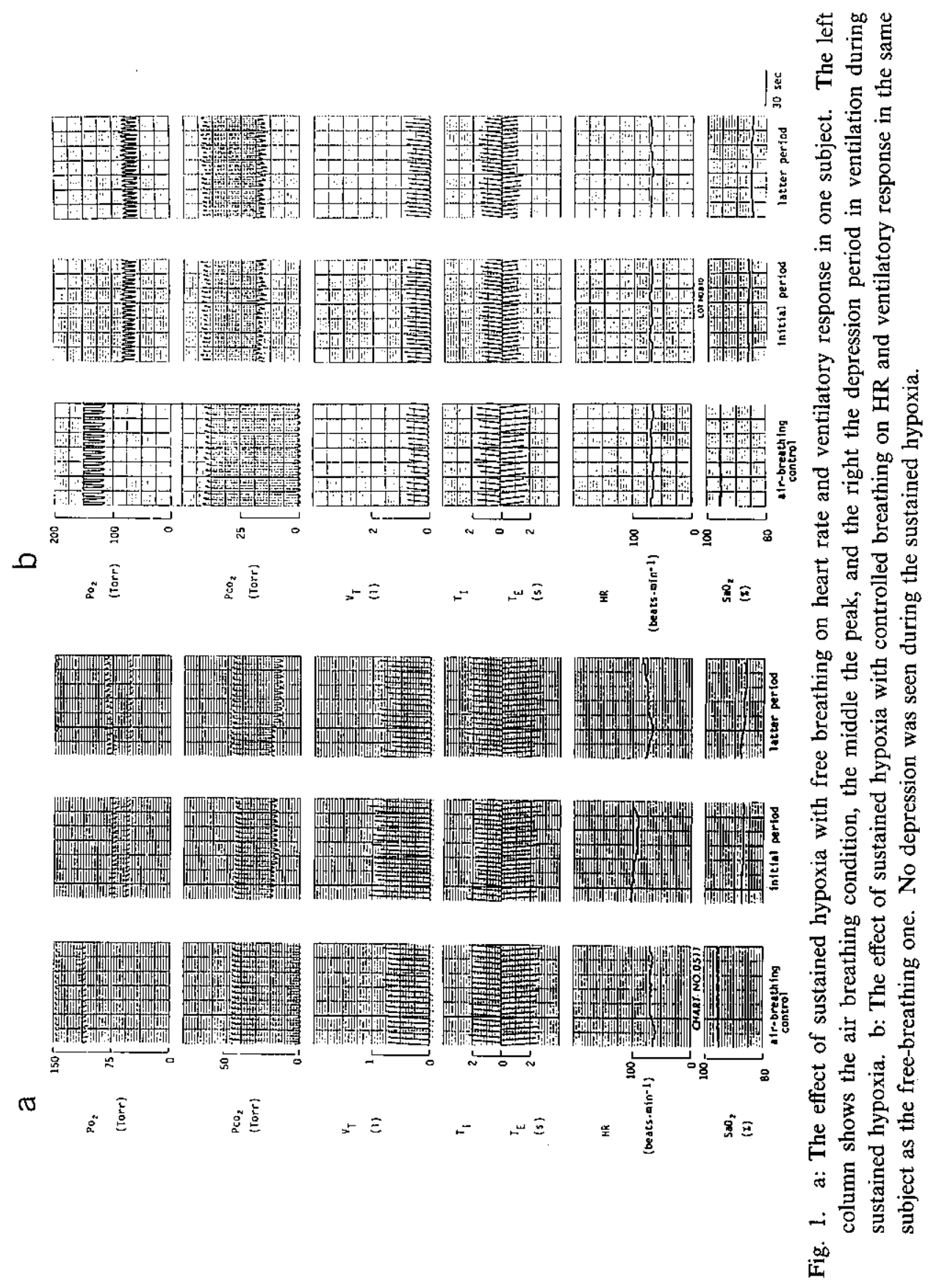

Vol. 42, No. 6, 1992 

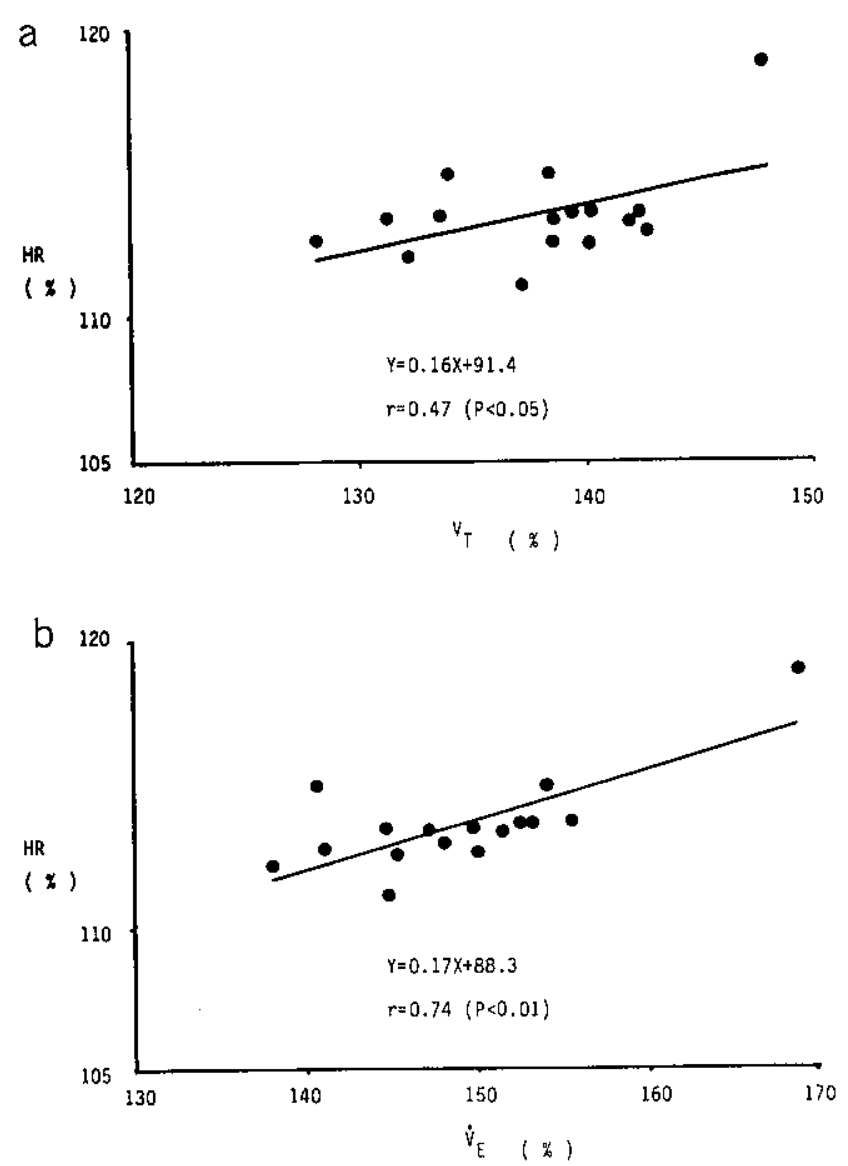

Fig. 2. Relationships between \% increase from control in $V_{T}$ and HR (a) and in $\dot{V}_{E}$ and HR (b) obtained from 8 subjects with sustained hypoxic breathing. Each point represents the average of consecutive observations at 1 -min intervals during hypoxic exposure with spontaneous breathing.

neous hypoxic breathing disappeared (Table 2).

Table 3 shows the detailed data of the two subjects who underwent both experiments. Their results show good agreement when $V \mathrm{~T}$ and $f$ were controlled to prevent the biphasic ventilatory response.

\section{DISCUSSION}

The present study demonstrated that not only ventilation but also HR response to sustained hypoxia was biphasic.

Since both ventilation and HR initially increased and then gradually decreased in a parallel fashion during hypoxic exposure, a good linear correlation between $\dot{V}_{\mathrm{E}}$ 
Table 2. The time-course of measured parameters before and during hypoxic challenge with controlled breathing obtained from 5 subjects.

\begin{tabular}{|c|c|c|c|c|}
\hline & \multirow{3}{*}{ Air-breathing } & \multicolumn{3}{|c|}{ Sustained isocapnic hypoxia } \\
\hline & & \multirow{2}{*}{$\frac{\text { Initial period }}{5 \text { th min }}$} & \multicolumn{2}{|c|}{ Latter period } \\
\hline & & & 10 th $\min$ & 15th $\min$ \\
\hline$P_{\mathrm{ET}_{\mathrm{O}_{2}}}$ (Torr) & $99.6 \pm 9.4$ & $49.6 \pm 5.2^{* *}$ & $49.6 \pm 4.8^{* *}$ & $49.4 \pm 4.5^{* *}$ \\
\hline$P \mathrm{ET}_{\mathrm{CO}_{2}}$ (Torr) & $43.2 \pm 2.2$ & $43.3 \pm 3.3$ & $43.6 \pm 3.0$ & $43.4 \pm 2.8$ \\
\hline$V \Upsilon(l)$ & $\begin{array}{l}0.59 \pm 0.16 \\
(100)\end{array}$ & $\begin{array}{c}0.87 \pm 0.14^{* * *} \\
(157.1)\end{array}$ & $\begin{array}{c}0.84 \pm 0.14^{* *} \\
\quad(152.2)\end{array}$ & $\begin{array}{l}0.84 \pm 0.11^{* *} \\
\quad(152.2)\end{array}$ \\
\hline$f$ (breaths/min) & $\begin{array}{c}11.9 \pm 1.67 \\
(100)\end{array}$ & $\begin{array}{c}16.7 \pm 1.79^{* *} \\
(141.3)\end{array}$ & $\begin{array}{c}16.5 \pm 1.66^{* *} \\
(139.1)\end{array}$ & $\begin{array}{c}16.8 \pm 1.89^{* *} \\
(140.4)\end{array}$ \\
\hline$\dot{V} \mathbf{E}(l / \min )$ & $\begin{array}{c}6.84 \pm 1.44 \\
(100)\end{array}$ & $\begin{array}{c}14.3 \pm 1.72^{* * *} \\
(218.8)\end{array}$ & $\begin{array}{c}13.7 \pm 1.65^{* * *} \\
(207.8)\end{array}$ & $\begin{array}{c}13.8 \pm 1.17^{* *} \\
(212.6)\end{array}$ \\
\hline HR (beats/min) & $\begin{array}{c}62.5 \pm 6.6 \\
(100)\end{array}$ & $\begin{array}{c}74.7 \pm 12.8^{* *} \\
(119.8)\end{array}$ & $\begin{array}{c}74.0 \pm 12.9^{* *} \\
(118.7)\end{array}$ & $\begin{array}{c}74.1 \pm 13.8^{* * *} \\
\quad(120.2)\end{array}$ \\
\hline
\end{tabular}

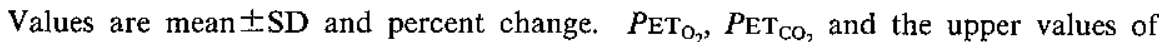
other parameters are the mean of absolute values obtained from 5 subjects. The lower figures in parentheses show the average response in terms of percent change in each subject. **Significantly changed from control value at $1 \%$ level. No biphasic ventilatory and HR changes are seen during sustained hypoxia.

and HR was found (Fig. 2b). Furthermore, a similar correlation was observed between $V_{T}$ and HR (Fig. 2a), and a lack of biphasic HR response was confirmed by Experiment 2, where $V_{\mathrm{T}}$ was maintained constant. This suggested that the Hering-Breuer inflation reflex [8-10] plays an important role in the positive $\dot{V}_{\mathrm{E}-\mathrm{HR}}$ and $V_{\mathrm{T}}-\mathrm{HR}$ relationships.

Putative neurochemicals such as adenosine or GABA have been reported to affect cardiovascular activities [25-30]. For example, adenosine initially produces bradycardia due to delayed $\mathrm{AV}$ nodal conduction and inhibits noradrenaline release through the presynaptic receptor $[25,30]$, followed by tachycardia and increased Bp with respiratory stimulation $[25,30]$. Accordingly, the possible roles of these neurochemicals accumulated during hypoxic challenge cannot be completely excluded in determining biphasic $\mathrm{HR}$ response. However, if the biphasic ventilatory response is simply derived from the adaptation by the afferent peripheralchemoreceptor activity as suggested by Khamnei and Robbins [6], Bascom et al. [5], and our previous study [7], a significant role of these chemical agents in the brain stem seems unlikely.

We also measured blood pressure, adrenaline, noradrenaline, and $\mathrm{K}^{+}$. It has been demonstrated that cardiovascular responses during acute hypoxia are stabilized at 5 [31], 15 [32], or $30 \mathrm{~min} \mathrm{[33]} \mathrm{from} \mathrm{the} \mathrm{onset} \mathrm{of} \mathrm{isocapnic} \mathrm{hypoxia.}$ Systolic blood pressure slightly increased soon after the hypoxic challenge but diastolic blood pressure gradually decreased during hypoxic exposure. Although 


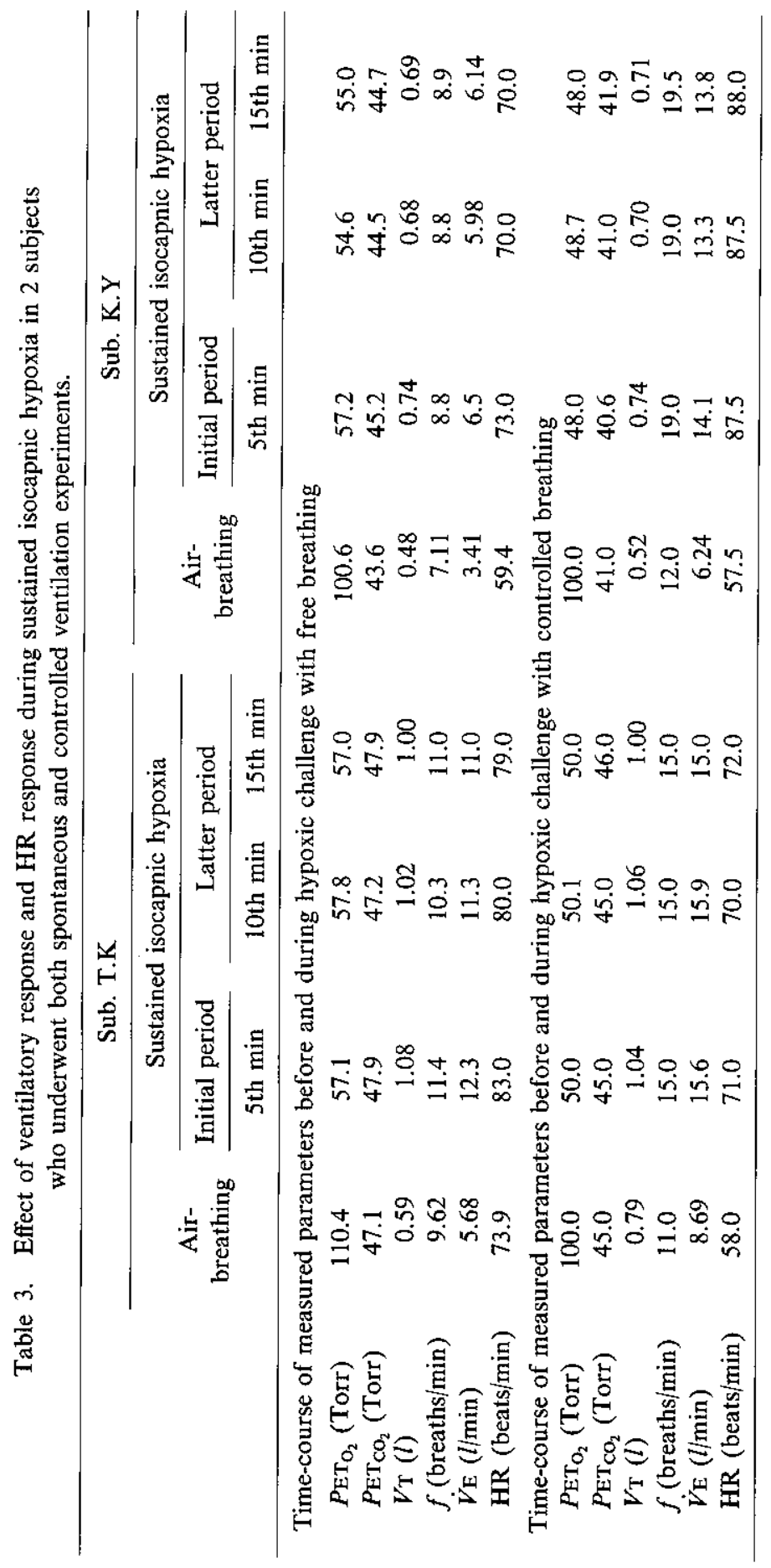


these blood pressures did not undergo significant changes, pulse pressure was observed to have increased significantly at $6,8,9$, and $11 \mathrm{~min}$ during hypoxia, but noradrenaline did not change. The effect of adrenaline has been characterized as inducing augmented systolic blood pressure and decreased diastolic blood pressure, with no alteration in mean blood pressure [34]. Our results coincided with those findings. While adrenaline gradually increased, the time-course of the ventilatory and HR changes differed from that of adrenaline; that is, augmentation was faster, followed by a gradual decay. Therefore, any direct interrelationship between adrenaline or noradrenaline and ventilatory or HR biphasic response is unlikely. An increased catecholamine release has been observed only after ischemic periods longer than $10 \mathrm{~min}$ in the isolated globally ischemic rabbit heart [19]. This finding coincides with our result that adrenaline increased gradually and attained a significant level only after more than 10 min of hypoxic exposure.

Although hypoxia increased the release of $\mathrm{K}^{+}$in animal studies [19-21], the present results showed a decreasing tendency rather than that of an increase. We assume that the difference between the previous results and our data may be ascribed to species differences and degree of hypoxia. $\mathrm{K}^{+}$also did not seem to influence ventilatory and cardiovascular response because these responses were augmented by hypoxia without any $\mathrm{K}^{+}$elevation. Recent studies have explored the relation between the release of endogenous catecholamines, the administration of exogenous catecholamines, and changes in extracellular $\mathbf{K}^{+}$concentrations $[19,24$, 35]. Those studies observed that the elevation of extracellular catecholamine concentration had an inhibitory effect on the time-course of extracellular $\mathbf{K}^{+}$ augmentation, which appears to support our results.

Any intentional control for maintaining elevated ventilation during hypoxic drive will be considerably affected by the higher CNS activities. For example, Goodwin et al. [36] demonstrated that the magnitude of central command increased when their subject maintained constant muscle tension and HR, ventilation, and blood pressure increased in parallel. When combining the CNS excitation with hypoxic excitation, effective elevation of sympathetic activity, and catecholamine release may be expected. If this is the cause, progressive HR elevation could have been observed in Experiment 2. However, such finding was not seen, as shown in Table 2.

A few other factors have been reported to affect HR during different respiratory activities, such as positive and negative intrathoracic pressure [37] and the augmented lungs volume [38]. As can be seen in Table 2, increment in tidal volume was about 0.41 and accordingly about $2 \mathrm{cmH}_{2} \mathrm{O}$ in intrathoracic pressure can be expected to fluctuate more than the control. These small changes in the physical factors may not substantially contribute to the present results.

The helpful cooperation of Chiba University medical students is gratefully acknowledged. We also thank Mr. W. Nakamura for his skilled technical assistance and advice. 


\section{REFERENCES}

1. Degoedl ABJ: Effects of brain hypoxia on ventilation. Eur Respir J 1: 184-190, 1988

2. Easton PA, Slykerman LJ, and Anthonisen NR: Ventilatory response to sustained hypoxia in normal adults. J Appl Physiol 61: 906-911, 1986

3. Ahn B, Honda Y, Masuda A, Pertersen ES, and Sakakibara Y: Comparison of ventilatory and circulatory responses to sustained hypoxia in man. J Physiol (Lond) 417: 114P, 1989

4. Vizek M, Cheryz KP, and John VW: Biphasic ventilatory response of adult cats to sustained hypoxia has central origin. J Appl Physiol 63: 1658-1664, 1987

5. Bascom DA, Clement ID, Cunningham DA, Painter R, and Robbins PA: Changes in peripheral chemoreflex sensitivity during sustained, isocapnic hypoxia. Respir Physiol 82: $161-176,1990$

6. Khamnei S and Robbins PA: Hypoxic depression of ventilation in humans: Alternative models for the chemoreflexes. Respir Physiol 81: 117-134, 1990

7. Tanaka M, Kimura H, Kunimoto F, Sakuma T, Kurono T, Hasako K, Uruma $T$, Kuriyama $\mathrm{T}$, and Honda $\mathrm{Y}$ : Effect of sustained hypoxia on ventilatory and heart rate responses in carotid body-resected humans. Jpn J Appl Physiol 22: 81-88, 1992.

8. Daly, M DE B and Hazzledine JL: The effects of artificially induced hyperventilation on the primary cardiac reflex response to stimulation of the carotid bodies in the dog. $\mathbf{J}$ Physiol (Lond) 168: 872-889, 1963

9. Crocker EF, Johnson RO, Korner PI, Uther JB, and White SW; Effects of hyperventilation on the circulatory response of the rabbit to arterial hypoxia. J Physiol (Lond) 199: 267-282, 1968

10. Coleridge JCG and Coleridge HM: Chemoreflex regulation of the heart. In: Handbook of Physiology, Section 2, The Cardiovascular System, ed. Berne, RM, Am Physiol Soc, Bethesda, Vol 1, pp 653-676, 1979

11. Bonora $\mathbf{M}$ and Gautier $\mathrm{H}$ : Influence of dopamine and noradrenaline on the central ventilatory response to hypoxia in conscious cats. Respir Physiol 71: 11-24, 1988

12. Burr $D$ and Sinclair JD: The effect of adenosine on respiratory chemosensitivity in the awake rat. Respir Physiol 72: 47-58, 1988

13. Javaheri S, Teppema LJ, and Evers JAM: Effects of aminophylline on hypoxemiainduced ventilatory depression in the cat. J Appl Physiol 64: 1837-1843, 1988

14. Long WA and Lawson EE: Neurotransmitters and biphasic respiratory response to hypoxia. J Appl Physiol 57: 213-222, 1984

15. Runold M, Lagercrantz H, Prabhakar NR, and Fredholm BB: Role of adenosine in hypoxic ventilatory depression. J Appl Physiol 67: 541-546, 1989

16. Srinivason $\mathrm{M}$, Lagercrantz $\mathrm{H}$, and Yamamoto $\mathrm{X}$ : A possible dopaminergic pathway mediating hypoxic depression in neonatal rabbits. J Appl Physiol 67: 1271-1276, 1989

17. Rose CE, Althaus JA Jr, Kaiser DL, Miller ED, and Carey RM: Acute hypoxemia and hypercapnia: Increase in plasma catecholamines in conscious dogs. Am J Physiol 245: H924-929, 1983

18. Rowell LB, Johnson DG, Chase PB, Comess KA, and Seals DR: Hypoxemia raises muscle sympathetic activity but not norepinephrine in resting humans. J Appl Physiol 66: $1736-1743,1989$ 
19. Wilde AM, Peters RJG, and Janse MJ: Catecholamine release and potassium accumulation in the isolated globally ischemic rabbit heart. Cell Cardiol 20: 887-896, 1988

20. Acker $\mathbf{H}$ : Measurements of potassium changes in the cat carotid body under hypoxia and hypercapnia. Pflügers Arch 375: 229-232, 1979

21. Estavillo JA, Nye PCG, Paterson DJ, and Terry M: The effect of hypoxia on arterial plasma potassium concentration in the cat. J Physiol (Lond) 403: 97P, 1988

22. Linton RAF and Band DM: The effect of potassium on carotid chemoreceptor activity and ventilation in the cat. Respir Physiol 59: 65-70, 1975

23. Nishino $T$ and Lahiri $S$ : Effects of dopamine on chemoreflexes in breathing. J Appl Physiol 50: 892-897, 1981

24. Elfellah MS and Reid JL: The role of skeletal muscle $\beta$-adrenoreceptors in the regulation of plasma potassium. J Auton Pharmacol 7: 175-184, 1987

25. Biaggioni I, Olafsson B, Robertson RM, Hollister AS, and Robertson D: Cardiovascular and respiratory effects of adenosine in conscious man. Evidence for chemoreceptor activation. Circ Res 61: 779-786, 1987

26. Defeudis FV: GABA - an inhibitory neurotransmitter that is involved in cardiovascular control. Pharmacol Res Commun 14: 567-575, 1982

27. Dimicco JA: Evidence for control of cardiac vagal tone by benzodiazepine receptors. Neuropharmacology 26: 553-559, 1987

28. Fuller RW, Maxwell DL, Conradson TBG, Dixon CMS, and Brances PJ: Circulatory and respiratory effects of infused adenosine in conscious man. Br J Clin Pharmacol 24: 309-317, 1987

29. Machado $\mathrm{BH}$ and Brody MJ: Role of the nucleus ambiguus in the regulation of heart rate and arterial pressure. Hypertension 11: 602-607, 1987

30. Watt AH and Routledge PA: Transient bradycardia and subsequent sinus tachycardia produced by intravenous adenosine in healthy adult subjects. Br J Clin Pharmacol 21: 533-536, 1987

31. Thilenius OG, Hoffer PB, Fitzgerald RS, and Perkins JF Jr: Response of pulmonary circulation of rest, unanesthetized dogs to acute hypoxia. Am J Physiol 206: 867-874, 1964

32. Bing OHL, Keefe JF, Wolk MJ, Lipana JG, Mcintyrea KM, and Levine HJ: Cardiovascular response to hypoxia and varying $P_{\mathrm{CO}_{2}}$ in the awake dog. J Appl Physiol 27: 204208, 1969

33. Borgia JF and Horvath SM: Effects of acute prolonged hypoxia on cardiovascular dynamics in dogs. J Appl Physiol 43: 784-789, 1977

34. Allwood, MJ, Cobbeold AF, and Ginsburg J: Peripheral vascular effects of noradrenaline, isopropylnoradrenaline and dopamine. Br Med Bull 19: 132-136, 1963

35. Struthers AD, Reid JL, Whitesmith R, and Rodger JC: Effect of intravenous adrenaline on electrocardiogram, blood pressure, and serum potassium. Br Heart J 49: 90-93, 1983

36. Goodwin GM, McCloskey DI, and Mitchell $\mathrm{JH}$ : Cardiovascular and respiratory response to changes in central command during isometric exercise at constant muscle tension. J Physiol (Lond) 226: 173-190, 1972

37. Song SH, Lee WK, Chung YA, and Hong SK: Mechanism of apneic bradycardia in man. J Appl Physiol 27: 323-327, 1969

38. Angelone A and Coulter NA Jr: Heart rate response to held lung volume. J Appl Physiol 20: 464-468, 1965 